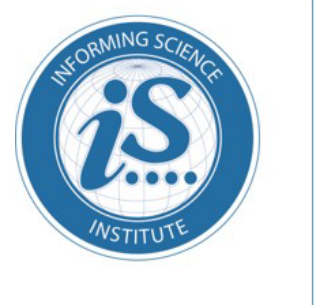

Interdisciplinary Journal of E-Skills and Lifelong Learning

An Official Publication

of the Informing Science Institute

InformingScience.org

\title{
REMAINING CONNECTED WITH OUR GRADUATES: A Pilot Study
}

$\begin{array}{lll}\text { Joy Penman* } & \begin{array}{l}\text { Monash University, Melbourne, } \\ \text { Australia }\end{array} & \text { jov.penman@monash.edu } \\ \text { Eddie Robinson } & \begin{array}{l}\text { Monash University, Melbourne, } \\ \text { Australia }\end{array} & \text { eddie.robinson@monash.edu } \\ \text { Wendy Cross } & \begin{array}{l}\text { Federation University, Berwick, } \\ \text { Australia }\end{array} & \text { w.cross@,federation.edu.au }\end{array}$

\section{ABSTRACT}

Aim/Purpose

This study aims to determine where nursing students from a metropolitan university subsequently work following graduation, identify the factors that influence decisions to pursue careers in particular locations, ascertain educational plans in the immediate future; and explore the factors that might attract students to pursue postgraduate study.

Background The global nursing shortage and high attrition of nursing students remain a challenge for the nursing profession. A recurrent pattern of maldistribution of nurses in clinical specialities and work locations has also occurred. It is imperative that institutions of learning examine their directions and priorities with the goal of meeting the mounting health needs of the wider community.

Methodology Qualitative and quantitative data were obtained through an online 21-item questionnaire. The questionnaire gathered data such as year of graduation, employment status, the location of main and secondary jobs, the principal area of nursing activity, and plans for postgraduate study. It sought graduates' reasons for seeking employment in particular workplaces and the factors encouraging them to pursue postgraduate study.

Contribution This study is meaningful and relevant as it provided a window to see the gaps in higher education and nursing practice, and opportunities in research and collaboration. It conveys many insights that were informative, valuable and illuminating in the context of nurse shortage and nurse education. The partnership with hospitals and health services in providing education and support at the workplace is emphasized.

Findings Twenty-three students completed the online questionnaire. All respondents were employed, 22 were working in Australia on a permanent basis (96\%), 19 in

Accepting Editor Fay Sudweeks | Received: October 26, 2018 | Revised: December 2, December 13, 2018 , February 26, 2019 | Accepted: February 28, 2019.

Cite as: Penman, J., Robinson, E., \& Cross, W. (2019). Remaining connected with our graduates: A pilot study. Interdisciplinary Journal of e-Skills and Lifelong Learning, 15, 43-57. https://doi.org/10.28945/4243

(CC BY-NC 4.0) This article is licensed to you under a Creative Commons Attribution-NonCommercial 4.0 International License. When you copy and redistribute this paper in full or in part, you need to provide proper attribution to it to ensure that others can later locate this work (and to ensure that others do not accuse you of plagiarism). You may (and we encourage you to) adapt, remix, transform, and build upon the material for any non-commercial purposes. This license does not permit you to use this material for commercial purposes. 
Recommendations for Practitioners

Recommendations for Researchers

Impact on Society

Future Research

Keywords urban areas (83\%) with three in regional/rural areas (13\%), and one was working internationally $(4 \%)$. This pilot study revealed that there were varied reasons for workplace decisions, but the most common answer was the opportunity provided to students to undertake their graduate year and subsequent employment offered. Moreover, the prevailing culture of the organization and highquality clinical experiences afforded to students were significant contributory factors. Data analysis revealed their plans for postgraduate studies in the next five years $(61 \%)$, with critical care nursing as the most popular specialty option. The majority of the respondents (78\%) signified their interest in taking further courses, being familiar with the educational system and expressing high satisfaction with the university's program delivery.

The results of the pilot should be tested in a full study with validated instruments in the future. With a larger dataset, the conclusions about graduate destinations and postgraduate educational pursuits of graduates would be generalizable, valid and reliable.

Further research to explore how graduates might be encouraged to work in rural and regional areas, determine courses that meet the demand of the market, and how to better engage with clinical partners are recommended.

It is expected that the study will be extended in the future to benefit other academics, service managers, recruiters, and stakeholders to alert them of strategies that may be used to entice graduates to seek employment in various areas and plan for addressing the educational needs of postgraduate nursing students. The end goal is to help enhance the nursing workforce by focusing on leadership and retention.

Future directions for research will include canvassing a bigger sample of alumni students and continuously monitoring graduate destinations and educational aspirations. How graduates might be encouraged to work in rural and regional areas will be further explored. Further research will also be undertaken involving graduates from other universities and other countries in order to compare the work practice of graduates over the same time frame.

nursing, graduate destinations, educational aspirations, clinical experiences

\section{INTRODUCTION}

Maintaining a sustainable health workforce remains a significant challenge for Australia. The challenge stems from a population living longer but with more complex health problems, spiralling costs of treatment, and increasing consumer demands and expectations (Health Workforce Australia [HWA], 2014a). The HWA (2014a) heralds the inevitable shortage of nurses owing to this population pattern, as well as an ageing nurse workforce and increasing attrition rates. Current projections estimate a shortage of as many as 85,000 nurses by 2025 , and 123,000 nurses by 2030 . These projections provide key stakeholders with the opportunities to develop and implement strategic directions to address the anticipated shortage in the nursing workforce. Other related issues of concern in contemporary nursing include the maldistribution of nurses in various locations and the need to meet educational and lifelong learning needs of graduates.

The shortage of nurses is not unique to Australia. Both the western and eastern countries report the seriousness of this problem. The figures from North America (Sigma Theta Tau, n.d.), the United Kingdom (UK) (Rafferty, 2018), and Asian countries like Singapore (Asia Pacific, 2018) reveal a short supply of nurses. The reasons may vary, with population growth, declining new nurse recruits, comorbidities, an ageing workforce, among them (Reinhard, Redfoot, \& Cleary, 2008), but the impact 
on care and survival are the same. Consequently, the employment of internationally qualified nurses has spiralled. In America alone, the number of international nurses grew by 93,036 between 2002 and 2006, and now exceeds the number of native-born nurses.

The problem calls for institutional responses at various levels of society, particularly the public and private sectors. Various innovations and initiatives have been implemented with the objective of alleviating the nurse shortage in Australia. The HWA (2014b, pp. 2-3) emphasised the need for "coordinated action for system-wide uptake" approach encompassing major areas such as "leadership, retention and productivity." It had been identified that work capacity must be built (leadership), early career preparation and workplace support must be provided (retention), and innovation in the workplace encouraged (productivity). Other countries are also preparing for the same pending massive shortage.

An exploratory study is to be undertaken to determine the graduate destinations and postgraduate educational pursuits of graduates of a metropolitan Australian university. However, before that occurs, a pilot study is undertaken first to test the methods and procedures in preparation for the largescale study. The instrument to be used needs to be validated and refined for use to a larger-sized population. After examining the feasibility of the study, more extensive data will be gathered that will allow generalised conclusions about graduate destinations and educational pursuits of graduates.

Thus, a retrospective study was conducted to access information and experiences of past students concerning their employment destinations and educational aspirations. The objectives of this pilot study were to (1) determine where students subsequently work following graduation, (2) identify the factors that influenced their decisions to pursue careers in either urban, regional/rural, remote or international locations, (3) determine their educational plans in the immediate future, and (4) explore the factors that might attract them to pursue postgraduate study with the University or elsewhere.

\section{LITERATURE REVIEW}

The nursing workforce in Australia is under pressure from several quarters. The nurses are ageing as reflected in both the increasing average age of nurses (from 44.3 years in 2009, 44.6 years in 2012, to 44.4 years in 2015) and the percentage of those aged 55 years and over (from 19.8 per cent in 2009 to 23.1 per cent in 2012). This trend is expected to continue, according to HWA (2014a) and the National Health Workforce Dataset (NHWD, 2016).

In $2016,89.1 \%$ of the nursing workforce was female, indicating nurses are more likely to be women (NHWD, 2016). From 2013 to 2016, the male proportion increased by $0.5 \%$ to $10.9 \%$, representing an increase of 3,419, with males aged between 23-34 years increasing by 1,867. These figures showed very modest increase by comparison to the female numbers; the male gender was and still is remarkably under-represented in a pool of over 360,000 nurses and midwives registered in Australia in 2015.

The majority of Australian registered nurses were employed in the medical, surgical, and mixed med$\mathrm{ical} /$ surgical areas $(23 \%$ or approximately 58,000$)$, followed by aged care $(10 \%$ or approximately 25,100) in 2012 (HWA, 2014a). While nurses were found in clinical settings, including aged care, medical/surgical, peri-operative, mental health, and emergency, there are fewer nurses in research, policy, and health promotion. Also, $56.2 \%$ of the workforce was in the public sector, $34.3 \%$ in private, and 3\% in both, in 2016 (NHWD, 2016).

Moreover, disparities with distribution occurred across states and territories. Statistics showed that, in 2016, about 55.2\% of the nurses were located in New South Wales (28.2\%) and Victoria (27.1\%), and $20.3 \%$ were located in Queensland (NHWD, 2016). In the same year, $72.2 \%$ of the workforce $(227,568)$ worked in major cities, $17.8 \%(56,097)$ in inner regional, $8 \%(25,188)$ in outer regional and $2 \%$ in remote/very remote $(6,247)$ areas. Based on the ratio of the number of health professionals in an area's population, the numbers of registered nurses were highest in major cities, and least in outback locations. 
The shortage and maldistribution of nursing staff have led to the recruitment of internationally qualified nurses to fill the positions. The nursing workforce comprised of $80.4 \%(253,444)$ individuals who obtained their initial qualification/s in Australia, $0.4 \%(1,362)$ obtained one initial qualification in Australia and one overseas, and $17.7 \%(55,770)$ obtained their initial qualification(s) overseas (NHWD, 2016). The majority of those who had overseas qualifications came from England and India. While employment of qualified overseas nurses may be a solution, this arrangement brings with it problems and challenges (Limpangog, 2013), which are essential to examine, but are beyond the scope of this paper.

Succession planning is another problem besetting the workforce. New nurses need the best possible supportive structures to commence their career paths plus meet the needs and expectations of health service employers. To achieve this requires much collaborative planning and adequate support from the workplaces. Thus, it is vital that retention and attrition issues be addressed. For one, leadership is paramount; nurse managers creating a conducive work environment for nurses is crucial (HWA, 2014b).

Beecroft, Dorey and Wenten (2008) reported an American study to determine the relationship of new nurse turnover intent with individual characteristics, work environment and organizational factors. A prospective study was conducted from 1999 to 2006 involving new paediatric nurses ( $\mathrm{n}=889)$; logistic regression analysis was performed. The relationships between turnover intent and actual turnover were compared using Kaplan-Meier survivorship. Results showed that when new graduate nurses were satisfied with their jobs and felt committed to the organization, turnover intent decreased. Increased seeking social support to cope with the transition was associated with turnover intent.

The workplace environment is vital to consider when it comes to nurse recruitment and retention. The environment must be safe and supportive as this is critical to the graduate nurse transition and integration (Johnstone, Kanitsaki, \& Currie, 2008). The concept of support was re-defined recently and the critical barriers identified. The negative attitude of staff members toward new nurse graduates was a compelling factor impacting on retention. It was also found that essential for retention and satisfaction of new nurses were placements with well-staffed units and transition-to-work programs (Scott, Engelke, \& Swanson 2008).

In a Switzerland study on retention (Addor, Jeannin, Schwendimann, \& Roulet Jeannert, 2017), it was revealed that half $(n=287$ ) of the participants left the workplace, or nursing altogether, at least once. The reasons behind leaving employment or nursing included personal choices, work-family conflict, heavy schedules, high workload, underused skills, lack of participation in decision-making, or unsupportive nursing management. In a study examining the relationships between authentic leadership and work engagement by Giallonardo, Wong, and Iwasiw (2010) using a predictive non-experimental survey design, it was found that job satisfaction was significantly associated with these two factors. Moreover, Cowin and Hengstberger-Sims (2005) reported that self-concept might provide the reason for graduate retention. Monitoring of self-concept throughout the transitional period for new nurses could lead to early detection and appropriate intervention strategies, thereby improving retention.

The matter of continuing education of nurses is equally pertinent. Nurses opt to pursue postgraduate studies for various reasons including higher income and opportunities, as well as increase network and professional development. Hickey, Sumsion, and Harrison (2013) commented that intrinsic and extrinsic rewards influenced career development and decisions of undergraduates to pursue education and that work experiences such as prior clinical placements and employment support were noteworthy considerations. In the case of generalist nurses practising in rural and remote settings, continuing education was essential as they cared for clients with a wide variety of conditions, including critical care and emergency conditions. However, access to continuing education for these nurses could be problematic owing to distance and equity issues (Hendrickx \& Winters, 2017). It was imperative to provide continuing education to nurses working in said geographical locations, utilising re- 
cent advances in technology. In providing postgraduate studies for past graduate nurses, the incorporation of two strategies for the graduate online education setting was implemented with the purpose of promoting caring for self and others through online Caring Groups (Brown \& Wilson, 2016). The sites were well received by the participants in the study.

To recapitulate, the global nursing shortage and high attrition of nursing students and nurses remain a challenge for the profession. A recurrent pattern of maldistribution of nurses in clinical specialities and work locations has also occurred. It is imperative that tertiary institutions examine their directions and priorities with the goal of meeting the mounting health needs of the wider community. The continuous shortage has led to the need to employ nurses who qualified abroad (Cousins, Burrows, Cousins, Dunlop, \& Mitchell, 2016). It is paramount that the education provider understands the factors that influence decisions to seek and retain employment in particular locations (metropolitan, regional/rural or remote, international) and make students aware of the diverse career pathways of nursing graduates, whether clinical, education, or research. Crucial also is to better assist students who are considering a career in various areas of nursing and strengthen their readiness for practice. Another important consideration is determining the educational pursuits of the graduates. In knowing the alumni's future educational plans, the university is informed about how to meet their future educational needs and aspirations. By providing adequate contextual information, the adoption of the findings to other universities and contexts may be facilitated. It is expected that the study will be extended in the future to benefit other academics, service managers, recruiters, and stakeholders to alert them of strategies that may be used to entice graduates to seek employment in various areas and plan for addressing the educational needs of postgraduate nursing students. The end goal is to help enhance the nursing workforce by focusing on leadership and retention.

\section{METHODOLOGY}

In collecting information about the participants' employment destinations and educational aspirations, an observational design is most appropriate. Observational designs aim to discern and identify variables of interest, such as individual characteristics, knowledge, beliefs, and attitudes about a particular topic, phenomenon, or event (Shields \& Smyth, 2016). More specifically, the study is descriptive and retrospective.

A survey, using a questionnaire, was administered online. It was self-completed, measuring only onetime point. It accessed the required information and linked the present outcomes to past events. Quantitative and qualitative data were obtained from this survey. The quantitative data identified the locations of employment, educational plans for the future, as well as the factors contributing to decisions about employment and postgraduate education. The qualitative data gave access to selfdisclosed reasons relating to choice of employment area and factors that would entice graduates to undertake postgraduate studies.

\section{SAMPLE}

A sample of 23 students who qualified for the award of a degree in nursing in the calendar years 2011 to 2016 completed the online survey. It was decided that for the pilot, the survey would be opened only to recent graduates. The mean age was 33 years, the youngest being 23 years, the oldest 51 years. Nineteen (19) were females; four were males. Of the respondents, eight had completed the Bachelor's degree, ten the Master of Nursing Practice pre-registration program, and five the Bachelor of Nursing/Bachelor of Emergency Health program. Two graduated in 2012, one in 2013, five in 2014, ten in 2015, and five in 2016.

A total of 694 Bachelor of Nursing pre-registration graduates were registered in the Alumni list at the beginning of 2017, and they were initially contacted. Only 23 responded within the timeframe, indicating a very low response rate. A more significant sample, comprising all graduates, will be surveyed in the larger study. 


\section{DATA COLLECTION}

A graduate employment location and further educational aspirations questionnaire was developed, based on the yearly survey for Australian Health Practitioner Regulation Agency (AHPRA) registration, and distributed online. Not all the questions were taken from the AHPRA survey; additional questions on the reasons for employment destinations and educational pursuits were added. The final instrument was a 21 -item questionnaire with open- and closed-ended questions that gathered data such as demographics, year of graduation, current employment status, the location of primary and secondary jobs and principal area of nursing activity (Questions 1 to 12). The reasons that prompted the graduates to seek employment in their particular workplaces were also surveyed (Question 13). Responses as to graduates' educational needs and plans were gathered in Questions 14 to 17 . The factors that might encourage graduates to undertake postgraduate education were explored (Questions 18 and 19). Finally, responses regarding the value of continuing education and further comments were sought (Questions 20 and 21). The questionnaire did not require any revision after two graduates trialled it before it was administered online.

\section{ETHICAL CONSIDERATIONS}

A protocol for this research was submitted to the University Human Research Ethics Committee. Following approval, steps were undertaken to ensure that requirements were met.

\section{PROCEDURE}

Representation to the alumni about the study was made through the official committee of the University, which held the list of past students and their addresses who were potential participants. The questionnaire was sent to the graduates online. A letter introducing the study and requesting participation and an explanatory statement were attached to the questionnaire. The explanatory statement provided details of the research process in order to help potential participants decide whether to participate or not. Any query regarding the study was to be directed to the Executive Officer, University Human Research Ethics, whose contact details were provided on the explanatory statement.

\section{METHOD OF ANALYSIS}

Descriptive and frequency analyses were performed on the data collected. A frequency distribution was used to organise the data (Fisher \& Fethney, 2016). The occurrences or frequencies of responses were summarized and reported in tables and depicted in charts. For the qualitative data, content analysis was undertaken. Counting and reporting the frequency of concepts, words and behaviour mentioned in the data was undertaken (Creswell, 2003; Vaismoradi, Turunen, \& Bondas, 2013).

\section{RESULTS}

All respondents were employed, 22 were working in Australia on a permanent basis, except for one. Nineteen (19) respondents were working in urban areas with three in regional/rural areas, and one working internationally (See Figure 1). 


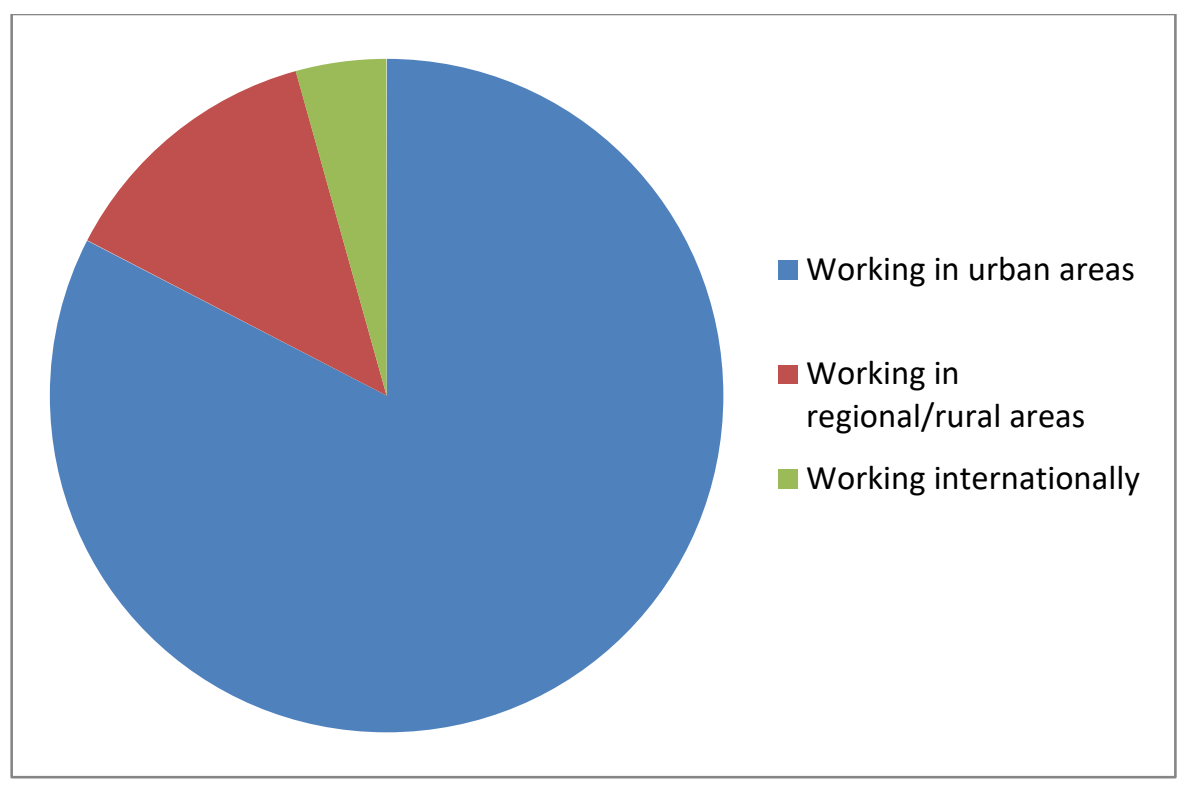

Figure 1. Employment location of students

Twenty-one (21) graduates had a single primary place of work; however, two reported that they had secondary jobs. Twenty-one (21) worked principally in clinical settings, one worked in research, and one worked both in a clinical and outside a clinical setting. The main task of work was standard nursing care for 21 nurses, and education and research for one participant.

When queried about the factors that influenced graduates' decision to pursue their careers in specific locations, it was revealed that there were multiple reasons for workplace decisions. The most common answer was the "opportunity provided to students to undertake their graduate year, and subsequent employment offered that helped students decide where to find employment." This was followed by the "culture of the healthcare setting" and by "positive clinical placement experiences" of students (See Table 1).

Table 1. Reasons for Choice of location

\begin{tabular}{|l|l|l|}
\hline REASON & Number* & Percent \\
\hline Opportunity to do a graduate year & 8 & 35 \\
\hline The culture of the organization & 7 & 30 \\
\hline Student placement experiences & 5 & 22 \\
\hline Passion and enjoyment & 4 & 17 \\
\hline Employer's request & 3 & 13 \\
\hline Career advancement & 2 & 9 \\
\hline Location & 2 & 9 \\
\hline Money & 1 & 4 \\
\hline
\end{tabular}

* Number of times the item was identified

On the topic concerning educational pursuits, analysis of the data revealed that 17 respondents had not undertaken any postgraduate study. The programs undertaken by the other six respondents include Master of Advanced Nursing (Mental Health), Graduate Certificate in Neonatal Care, Bachelor of Midwifery, Master of Advanced Practice (Midwifery), Postgraduate Certificate in Critical Care, 
Master of Advanced Nursing and undertaking Education subjects, and Postgraduate Critical Care. Fourteen (14) participants had plans for postgraduate study in the next five years, six were undecided, and three did not have plans (See Figure 2). Four (4) identified critical care as the nursing speciality they wished to pursue. Other speciality areas of interest included Emergency nursing, Cardiac nursing, Midwifery, Education, and Anatomy/Physiology/Pathophysiology.

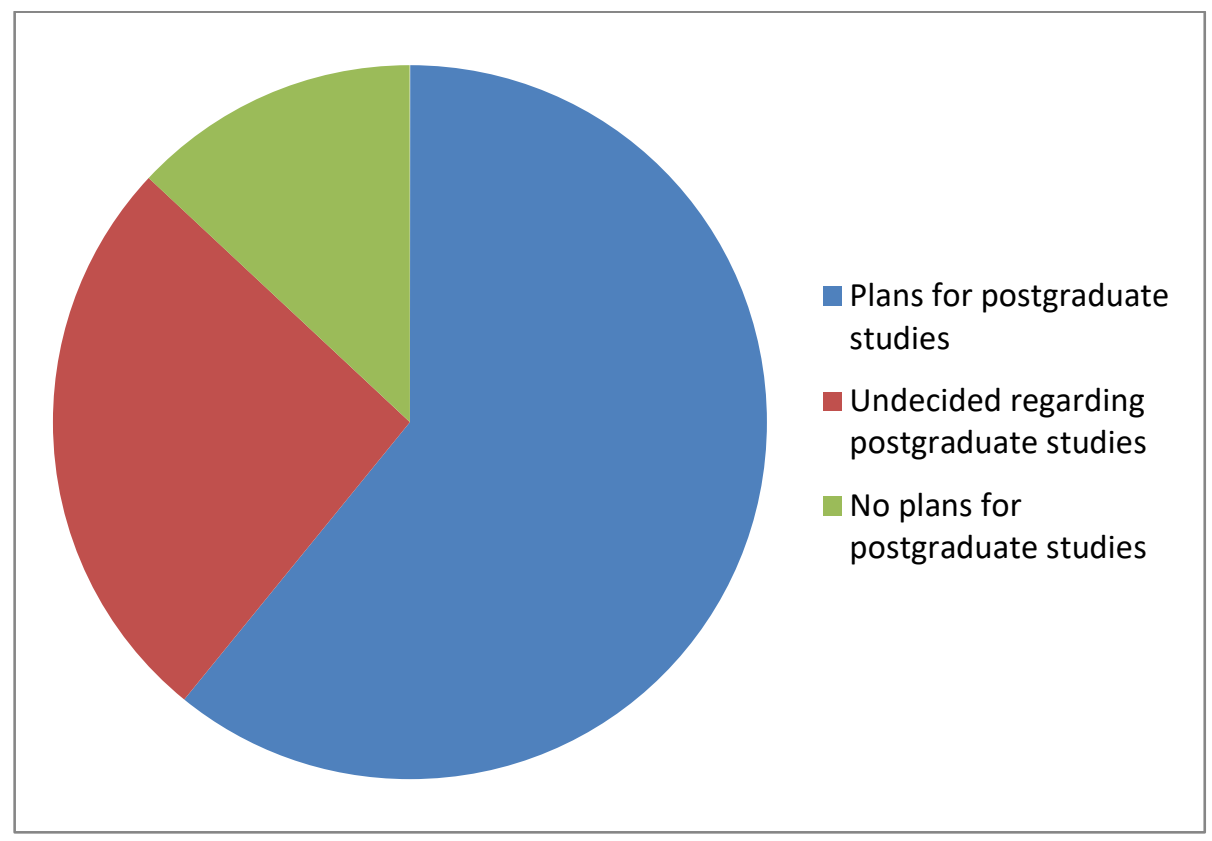

Figure 2. Pursuing postgraduate studies

The participants suggested multiple ways to entice past students to pursue postgraduate studies. Frequently recurring answers were: "good undergraduate learning experiences", "online" delivery of courses and "flexibility", and "the range of courses/programs being offered" (See Table 2).

Table 2. Factors to attract Graduates to Pursue Postgraduate Studies

\begin{tabular}{|l|c|c|}
\hline FACTOR & Number* & Percent \\
\hline Good experience during the undergraduate study & 6 & 26 \\
\hline If provided online & 5 & 22 \\
\hline The range of courses being offered & 4 & 17 \\
\hline Flexibility with work & 3 & 13 \\
\hline $\begin{array}{l}\text { Others (International Health / Neuroscience; scholarship; } \\
\text { location; word of mouth; progression into academia) }\end{array}$ & 5 & 22 \\
\hline
\end{tabular}

* Number of times the item was identified

Eighteen (18) participants signified their interest to study. However, they qualified that this applied only if they were government-supported places. Two (2) indicated a willingness to pay full fees, and if "it [the course] was good enough". Continuing education was necessary for 21 graduates. Table 3 summarises the reasons why continuing education is a priority for these alumni. 
Table 3. Importance of Continuing Education

\begin{tabular}{|l|c|c|}
\hline REASON & Number* & Percent \\
\hline Professional growth & 9 & 39 \\
\hline Career advancement & 4 & 17 \\
\hline Personal benefit & 4 & 17 \\
\hline Community/Patient care & 3 & 13 \\
\hline Work overseas & 1 & 4 \\
\hline
\end{tabular}

* Number of times the item was identified

The motivation for undertaking further education was the desire to grow personally and professionally. Closely related was a marked focus on employment outcomes and career advancement. Some quotations on the value of continuing education are included:

It [continuing education] is important for furthering knowledge in speciality areas.

Need to be able to provide the best care

The medical field is ever-changing, and further education can only benefit me, my colleagues, my workplace, and ultimately my patient care. You can never learn too much when it comes to health care provision

It is necessary for senior positions.

Yes as education is Power and knowledge is growth - become better at your job.

Always learning and improving to provide the best care for our community!

Table 4 summarises the specific strategies that might attract individuals to pursue postgraduate education from the graduates' perspectives. The recurring responses were "the courses students are looking for must be offered", "flexibility" in delivery, and adequate and assertive promotion. The latter referred to the exploration of promotional activities and the roles of advertising and marketing in promoting postgraduate studies.

Table 4. Strategies That Might Entice Individuals to Pursue Postgraduate Studies

\begin{tabular}{|l|c|c|}
\hline STRATEGY & Number* & Percent \\
\hline Availability of courses/subject content & 7 & 30 \\
\hline Flexibility/online/convenience & 5 & 22 \\
\hline $\begin{array}{l}\text { Actively inform students of the many opportunities avail- } \\
\text { able in post-grad studies }\end{array}$ & 3 & 13 \\
\hline Attractive career option & 2 & 9 \\
\hline Scholarship & 1 & 4 \\
\hline
\end{tabular}

* Number of times the item was identified

\section{DISCUSSION}

This section examines the major findings of the study. It focuses on the objectives that have been achieved, implications, relation to other similar studies, the meaning and relevance of the findings, and the limitations. 
The objectives of the pilot study have been achieved. The first objective was to determine where the students subsequently worked following graduation. It appeared that the location was decided by the opportunity provided to the students to undertake their graduate year and subsequent employment offered. However, the location was also determined by the prevailing culture of the workplace and by positive clinical placement experiences gained by the students. Similarly, Hickey et al. (2013) concluded that the experiences at the workplace, particularly the support available to students, influence career development and decision-making. In addition to practicum experiences, the location of work was also an essential factor. In a UK pilot study aimed at exploring the influence of clinical placements on final-year nursing students' career decisions, it was concluded that the experiences in the third year were a determining factor in their decision about their first employment position (Wareing, Taylor, Wilson, \& Sharples, 2017). The same authors highlighted the level of support of clinical staff as critical for recruitment and retention.

Nursing schools must continue recognising the value of strong partnerships with hospitals and health services in providing quality clinical placements. Dufault, Bartlett, Dagrosa, and Joseph (1992) reported on collaborative programs between industry and academia, the central outcome of which was an increase in students' competencies and learning. Other outcomes of the partnership between industry and academia included increased recruitment and retention of nurses in the hospitals and greater ease in their orientation and transition. The "turf" issues separating the two needs to be negotiated and the wall dividing them broken down.

The turnover rate of new graduate nurses is unusually high. Rhéaume, Clément, and LeBel (2010) studied why new graduate nurses intended to leave their current employer. Survey data were collected from 348 new graduate nurses over five years, beginning in 2004 and ending in 2008, in eastern Canada. Intention to leave was associated with the work environment, foundations for quality nursing care, and psychological empowerment. A similar trend was reported by Meyer, Shatto, Delicath, and von der Lancken (2017), who concluded that the clinical environment was a potent force for professional and job satisfaction and for the intention to stay in their position. This conclusion was corroborated by Shatto and Lutz (2017) who posited that a supportive environment free from bullying, a positive preceptor experience, and self-confidence are vital for retention to happen.

Various internship programs have been set up to facilitate the smooth transition of new graduates to the workforce. These programs are essential in assisting the movement of beginning nurses into special units, such as critical care, oncology, or neuroscience, which could be daunting for new graduates (Hartshorn, 1992; Price, Dilorio, \& Becker, 2000). These have the potential of improving the working conditions that nurses deem essential in their decisions to seek and maintain employment, whether in urban or regional areas.

The second objective was to identify the factors that influenced past students decisions to pursue careers in urban, regional/rural, remote, or international locations. The majority of the participants sought employment in the urban areas. Nursing students studying at metropolitan universities were likely to seek employment in metropolitan areas and unlikely to work in regional areas, a hypothesis that would be tested in the larger study. Similarly, graduates from regional/rural universities were more likely to stay and work there (Penman, Oliver, \& Petkov, 2003). However, it is critical that urban graduate nurses develop familiarity with nursing in regional areas and be attracted to consider employment options in these areas if the maldistribution of nurses in Australia is to be addressed.

Part of the solution to nursing shortages is to increase the number of student places in areas with nursing candidate gaps and to attempt to contribute significantly also to the regional workforce. Including regional nursing in the curriculum and forming strong partnerships with health organizations to improve awareness of employment opportunities in regional and rural areas are strategies that could be explored. We also need to consider how the university might meet regional and rural nurses' educational needs. Developing strong partnerships with industry (Valentín, 2000), establishing intern- 
ship programs, and offering courses/programs that are relevant can also contribute to achieving this purpose.

This study revealed another aspect worth investigating - gender issues. The sample of this study depicted a substantially smaller proportion of males $(17 \%)$ to females $(83 \%)$, representing the femaledominated nature of nursing. Other research findings also indicated that males were more likely to leave the course than females (McLaughlin, Muldoon, \& Moutray, 2010). Furthermore, those who completed the course thought that nursing was more appropriate for women. The prevalent stereotypes and gender bias inherent in the nursing culture tend to make the profession more challenging for males. With the current shortage of nurses, this gender bias is not helpful, and strategies to reduce/eliminate this are imperative.

The third objective that was achieved was concerned with determining the educational aspirations of past students. In this study, the majority wanted to further their education, and many were intrinsically and extrinsically motivated. However, the availability of government support was an important factor to consider in deciding about postgraduate education. In Australia, postgraduate studies rarely attract fees support from the government, and this places a financial burden on students. Therefore, a gap to bridge and opportunity to develop is how to make postgraduate education more accessible to these potential students.

The fourth objective was to explore the factors that might attract students to pursue postgraduate study with the University or elsewhere. The participants suggested multiple exciting and creative ways of accomplishing this. Emphasis was placed on making popular courses available. Some courses were currently unavailable at the University, and this meant that students needed to study outside their residential areas if they chose to undertake a course only offered elsewhere. The other alternative was to study online, but this meant limited contact with the tertiary provider. Universities in the 21 st century are driven by revenue and do not offer courses deemed unviable despite interest from potential students. An innovative collaboration between universities might be a solution to this limitation. Crossenrolment and cross-crediting by institutions of higher education have been shown to be beneficial as a model for collaboration in distance education (Pritchard \& Jones, n.d.).

Past students indicated their highly satisfying and positive university experience as a factor when considering postgraduate studies. This market with its readymade links to the University should be capitalised upon. One student commented, "Easy to go back and study as I am already familiar with the educational system", while another remarked, "The nursing lecturers are superb." Students who have had positive experiences with their university were likely to pursue further studies in the same university, another hypothesis that would be tested in the next phase of the study.

For some students, the perception of the value in education takes a consumerist view. They want 'value for money' (Kandiko \& Mawer, 2013). They wish to know the details of the time, facilities, and resources that will be invested in them. To support students' choice of postgraduate study, there should be more information and transparency over how the money is spent on teaching and learning activities, what qualifications academics have, and how teaching is structured and allocated.

This study is meaningful and relevant for several reasons. It provided a window to see the gaps in higher education and nursing practice, and opportunities in research and collaboration. It conveyed many insights that are informative, valuable, and illuminating in the context of nurse shortage and nurse education. The partnership with hospitals and health services in providing education and support at the workplace could not be overemphasised. A clinical environment that was satisfying, positive and nurturing was crucial for employment decision and retention. Increasing awareness of the opportunities available in regional/rural and remote areas was a strategy that might address the maldistribution of nurses, as well as reducing/eliminating gender bias. This study also confirmed that past students were keen about postgraduate studies realising its many benefits, but they have some hurdles to overcome to participate in further education. 
This pilot study has limitations as the data were derived from the responses of a small group of bachelor degree graduates between 2011 and 2016. Constrained by small numbers, the implications and recommendations are provisional. The results will be tested in a full study with validated instruments in the future. With a larger dataset, the conclusions about graduate destinations and postgraduate educational pursuits of graduates of a metropolitan Australian university will be generalizable, valid and reliable. The ultimate goal is to examine how the university is contributing towards producing a sustainable nurse workforce by providing education and training to future and continuing nurses.

\section{CONCLUSION}

This study has provided information about the destinations of students who completed an undergraduate nursing degree at a metropolitan campus. A significant proportion of the graduates subsequently worked in urban settings, and the reasons prompting them to work in metropolitan areas were clarified. These reasons were the opportunity provided to the students to undertake their graduate year, the offer of employment; the prevailing culture of the healthcare setting; and the students' positive clinical placement experiences. Providing highly satisfactory clinical placement experiences is paramount for recruitment and retention.

Equally important to consider is the provision of professional and educational support. The majority of the graduates deemed continuing education a priority and had plans to pursue postgraduate education if the University were to offer the right courses, deliver flexibly and/or online, and appropriately design courses for people who are working.

Future directions for research will include canvassing a bigger sample of alumni students, testing the hypotheses framed, and continuously monitoring graduate destinations and educational aspirations. How graduates might be encouraged to work in rural and regional areas will be further explored. Further research will also be undertaken involving graduates from other universities and other countries in order to compare the work practice of graduates over the same time frame.

\section{REFERENCES}

Addor, V., Jeannin, A., Schwendimann, R., \& Roulet Jeannert, F. (2017). Career paths of 1988 and 1998 nurse graduates in Switzerland: Nurses at work pilot study. Journal of Nursing Management, 25, 318-325. https://doi.org/10.1111/jonm.12469

Asia Pacific. (2018). Nurse shortage is a global problem. Retrieved from https://www.himssasiapac.org/contentlibrary/exclusive-articles/nurse-shortage-global-problem

Beecroft, P. C., Dorey, F., \& Wenten, M. (2008). Turnover intention in new graduate nurses: A multivariate analysis. Journal of Advanced Nursing, 62(1), 41-52. https://doi.org/10.1111/j.1365-2648.2007.04570.x

Brown, C. J., \& Wilson, C. B. (2016). One university making a difference in graduate education. Journal of Holistic Nursing, 34(4), 402-407. https://doi.org/10.1177/0898010116633319

Cousins, C., Burrows, R., Cousins, G., Dunlop, E., \& Mitchell, G. (2016). An overview of the challenges facing care homes in the UK. Nursing Older People, 28(9). https://doi.org/10.7748/nop.2016.e817

Cowin, L. S., \& Hengstberger-Sims, C. (2005). New graduate nurse self-concept and retention: A longitudinal survey. International Journal of Nursing Studies, 43, 59-70. https://doi.org/10.1016/j.ijnurstu.2005.03.004

Creswell, J. W. (2003). Research design: Qualitative, quantitative and mixed methods approaches (2nd ed.). Thousand Oaks CA: Sage Publications.

Dufault, M. A., Bartlett, B., Dagrosa, C., \& Joseph, D. (1992). A statewide consortium initiative to establish an undergraduate clinical internship program. Journal of Professional Nursing, 8(4), 239-244.

https://doi.org/10.1016/8755-7223(92)90085-D 
Fisher, M., \& Fethney, J. (2016). Analysing data in quantitative research. In Z. Schneider, D. Whitehead, G. LoBiondo-Wood, \& J. Haber, Nursing and midwifery research methods and appraisal for evidence-based practice (5th ed.) (pp. 213-235). Chatswood, NWS: Elsevier Australia.

Giallonardo, L. M., Wong, C. A., \& Iwasiw, C. L. (2010). Authentic leadership of preceptors: predictor of new graduate nurses' work engagement and job satisfaction. Journal of Nursing Management, 18(8), 993-1003. https://doi.org/10.1111/j.1365-2834.2010.01126.x

Hartshorn, J. C. (1992). Evaluation of a critical care nursing internship program. Journal of Continuing Education in Nursing, 23(1), 42-48.

Health Workforce Australia (2014a). Australia's future health workforce - Nurses overview. Retrieved from https://www.health.gov.au/internet/main/publishing.nsf/Content/34AA7E6FDB8C16AACA257D95001 12F25/\$File/AFHW\%20-\%20Nurses $\% 20$ overview $\% 20$ report.pdf

Health Workforce Australia (2014b). Nursing workforce sustainability - Improving nurse retention and productivity. Retrieved from https://www.health.gov.au/internet/main/publishing.nsf/Content/29418BA17E67ABC0CA257D9B0075 7D08/\$File/Nursing $\% 20$ Workforce $\% 20$ Sustainability $\% 20$ \%20Improving $\% 20$ Nurse $\% 20$ Retention $\% 20$ and $\% 20$ Productivity $\% 20$ report.pdf

Hendrickx, L., \& Winters, C. (2017). Access to continuing education for critical care nurses in rural or remote settings. Critical Care Nurse, 37(2), 66-71. Retrieved from http://ccn.aacnjournals.org/content/37/2/66.abstract

Hickey, N., Harrison, L., \& Sumsion, J. (2013). Transition to work and career destinations of double degree nurses. Contemporary Nurse, 45(1), 64-78. https://doi.org/10.5172/conu.2013.45.1.64

Johnstone, M.-J., Kanitsaki, O., \& Currie, T. (2008). The nature and implications of support in graduate nurse transition programs: Australian study. Journal of Professional Nursing, 24(1), 46-53. https://doi.org/10.1016/j.profnurs.2007.06.003

Kandiko, C. B., \& Mawer, M. (2013). Student expectations and perceptions of higher education. London: King's Learning Institute.

Limpangog, C. (2013). Migration as a strategy for maintaining a middle-class identity: The case of professional Filipino women in Melbourne. Austrian Journal of South-East Asian Studies, 6(2), 307-329. https://doi.org/10.4232/10.ASEAS-6.2-5

McLaughlin, K., Muldoon, O. T., \& Moutray, M. (2010). Gender, gender roles and completion of nursing education: A longitudinal study. Nurse Education Today, 30(4), 303-307. https://doi.org/10.1016/j.nedt.2009.08.005

Meyer, G., Shatto, B., Delicath, T., \& von der Lancken, S. (2017). Effect of curriculum revision on graduates' transition to practice. Nurse Education, 42(3), 127-132. https://doi.org/10.1097/NNE.0000000000000325

National Health Workforce Dataset (2016). The nursing and midwifery workforce. Retrieved from https://www.aihw.gov.au/about-our-data/our-data-collections/national-health-workforce-dataset

Penman, J., Oliver, M., \& Petkov, J. (2003). Where are our graduates: A retrospective study of employment location of Whyalla nursing graduates. In C Boylan \& B Hemmings (Eds.), Proceedings of the Society for the Provision of Education in Rural Australia 19th National Conference 2003: Global Focus - Local Partnerships, SPERA, Toowoomba, pp 105-115.

Price, M. E., DiIorio, C., \& Becker, J. K. (2000). The neuroscience nurse internship program: The description. Journal of Neuroscience Nursing, 32(6), 318-323. https://doi.org/10.1097/01376517-200012000-00005

Pritchard, A. L., \& Jones, D. R. (n.d.) Evaluative study of cross-crediting arrangements between distance education universities. Retrieved from https://books.google.com/books/about/Evaluative Study of Cross crediting Arra.html?hl=zh$\underline{\text { CN\&id }=\text { zwzuAAAAMAAJ\&utm source }=\text { gb-gplus-shareEvaluative }}$

Rafferty, A. M. (2018). Shortage of nurses in UK is affecting patient care and threatening lives. Retrieved from http://theconversation.com/shortage-of-nurses-in-uk-is-affecting-patient-care-and-threatening-lives$\underline{89734}$ 
Reinhard, S., Redfoot, D., \& Cleary, B. (2008). Health and long-term care: Are immigrant workers indispensable? Generations, 32(4), 24-30. Retrieved from http://web.ebscohost.com.proxy.lib.csus.edu/ehost/pdf?vid=2\&hid=9\&sid=7c07cd25-53c6-4b0e-8b6107bf9c2ab966\%40sessionmgr13

Rhéaume, A., Clément, L., \& LeBel, N. (2010). Understanding intention to leave amongst new graduate Canadian nurses: A repeated cross sectional survey. International Journal of Nursing Studies, 48, 490-500. https://doi.org/10.1016/j.ijnurstu.2010.08.005

Scott, E. S., Engelke, M. K., \& Swanson, M. (2008). New graduate nurse transitioning: necessary or nice? $A p$ plied Nursing Research, 21, 75-83. https://doi.org/10.1016/j.apnr.2006.12.002

Shatto, B., \& Lutz, L. M. (2017). Transition from education to practice for new nursing graduates: A literature review. Creative Nursing, 23(4), 248-254. https://doi.org/10.1891/1078-4535.23.4.248

Shields, L., \& Smyth, W. (2016). Common quantitative methods. In Z. Schneider, D. Whitehead, G. LoBiondoWood, \& J. Haber, Nursing and midwifery research methods and appraisal for evidence-based practice (5th ed) (pp. 143164). Chatswood, NWS: Elsevier Australia.

Sigma Theta Tau. (n.d.). Steep population growth resulting in a growing need for health care services. Retrieved from https://www.sigmanursing.org/why-sigma/about-sigma/sigma-media/nursing-shortageinformation/facts-on-the-nursing-shortage-in-north-america

Vaismoradi, M., Turunen, H., \& Bondas, T. (2013). Content analysis and thematic analysis: Implications for conducting a qualitative descriptive study. Nursing and Health Sciences, 15(3), 398-405. https://doi.org/10.1111/nhs.12048

Valentín, E. M. M. (2000), University-industry cooperation: A framework of benefits and obstacles. Industry and Higher Education, 14(3), 165-172. https://doi.org/10.5367/000000000101295011

Wareing, M., Taylor, R., Wilson, A., \& Sharples, A. (2017). The influence of placements on adult nursing graduates' choice of first post. British Journal of Nursing, 26(4), 228-233. https://doi.org/10.12968/bjon.2017.26.4.228

\section{BIOGRAPHIES}

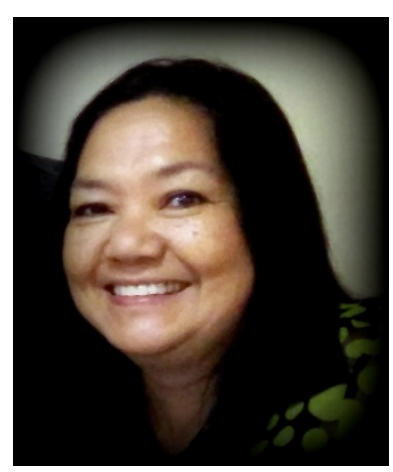

Dr Joy Penman is a Senior Lecturer in Nursing and Midwifery at the Monash University. She is the Coordinator of the Internationally Qualified Nurses program and Stream Lead of the Australian Nursing Studies. She has over thirty years teaching experience locally and abroad and many years nursing experience in various healthcare facilities. Joy has extensive experience in research and community engagement. In recognition of her contribution to these areas, she has been a recipient of multiple teaching, research and community service awards. Joy has been involved in various research projects. She is well published in peer-reviewed journals and books and has presented her work at national and international conferences. 


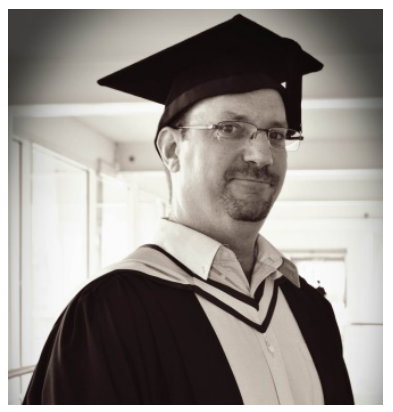

Eddie Robinson joined Monash University in February 2010 as a mental health nursing academic for the undergraduate nursing and midwifery students. He currently teaches into the Master of Nursing Practice (MNP) at Clayton campus. Eddie has extensive experience in public mental health positions varying from Adult in-patient, Psycho-social rehabilitation, Acute Community and Consultation Liaison role in the Emergency Department. Prior to commencement with Monash University, Eddie facilitated clinical placements for nursing and health undergraduate students throughout the mental health services of Peninsula Health. Eddie has a keen interest in the development of student preparation for the clinical field, support mechanisms for nurses in mental health and career development for mental health nurses.

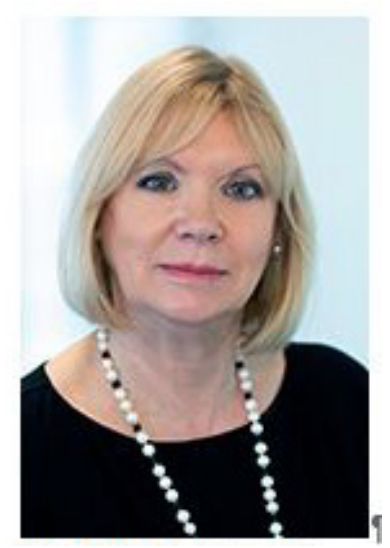

Professor Wendy Cross is the Dean of the School of Nursing and Healthcare Professions at Federation University, Australia. She is a National Mental Health Commissioner and is the immediate past Chair of the Council of Deans of Nursing and Midwifery, (Australia and New Zealand) and immediate past President of the Australian College of Mental Health Nurses.

Wendy has a Bachelor of Applied Science in Advanced Nursing from LaTrobe University a Master of Education by research (Ed Psych) from Monash University and a Doctor of Philosophy from the University of NSW, focusing on Transcultural Psychiatry.

She is widely sought for her expertise in mental health, education and governance and contributes to a number of organizations as a board director, external panel member and expert assessor.

Wendy had published over 100 articles across all domains (most peer-reviewed) and her primary research interests include mental health and resilience, clinical supervision, practice development, health service evaluation. She is experienced in broad-based research methods including both quantitative and qualitative paradigms. She is currently involved in a number of funded research projects related to mental health, resilience and evaluation of health services. 